Atmos. Meas. Tech., 3, 429-439, 2010

www.atmos-meas-tech.net/3/429/2010/

(C) Author(s) 2010. This work is distributed under

the Creative Commons Attribution 3.0 License.

\title{
A low power automated MAX-DOAS instrument for the Arctic and other remote unmanned locations
}

\author{
D. Carlson ${ }^{1}$, D. Donohoue ${ }^{1}$, U. Platt ${ }^{2}$, and W. R. Simpson ${ }^{1}$ \\ ${ }^{1}$ Geophysical Institute and Department of Chemistry, University of Alaska Fairbanks, Fairbanks, AK 99775-6160, USA \\ ${ }^{2}$ Institut für Umweltphysik, Universität Heidelberg, Heidelberg, Germany
}

Received: 27 August 2009 - Published in Atmos. Meas. Tech. Discuss.: 2 October 2009

Revised: 17 March 2010 - Accepted: 18 March 2010 - Published: 31 March 2010

\begin{abstract}
Multiple Axis Differential Optical Absorption Spectrometer (MAX-DOAS) systems are inherently very simple instruments, which have been shown to provide extremely useful information about a wide variety of environmental parameters. In order to exploit the potential of the technique we have developed a new field-deployable, passive MAX-DOAS system that is automated and uses little power $(<3 \mathrm{~W})$. This new instrument utilizes a fully enclosed scan head that protects all moving parts and optics from harsh environments. Instrument diagnostics, such as tilt monitoring and frost accumulation detection and removal, are integrated into the main data acquisition program, which then acts to remedy problems that were discovered. This full automation and data quality checking make this instrument ideal for long-term deployment at remote, unmanned locations around the world, such as in polar regions or in the monitoring of trace gas emissions from volcanoes. This instrument was recently integrated into an ice-tethered autonomous buoy and tested in Elson Lagoon, near Barrow, Alaska to monitor halogen chemistry in the Arctic. During this investigation, differential slant column densities (dSCDs) of $\mathrm{BrO}$ up to $6 \times 10^{14}$ molecules $/ \mathrm{cm}^{2}$ were observed. Typical spectral fit residual RMS optical densities were less than $6 \times 10^{-4}$ for solar zenith angles (SZA) $<80^{\circ}$ and a 6-min integration time. Here we describe the design concepts and performance of this new MAX-DOAS instrument through detailed analyses of spectral quality, power usage, possible instrument response biases, and typical instrument operations.
\end{abstract}

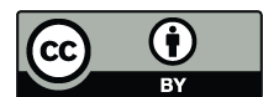

Correspondence to: W. R. Simpson (wrsimpson@alaska.edu)

\section{Introduction}

First used by Dobson and Harrison (1926) to measure atmospheric ozone, the technique of passive absorption spectroscopy has been in continual development for almost a century. Today, the advent of multi-wavelength array detectors, miniaturized electronics, and fiber optics has given rise to modern passive differential optical absorption spectroscopy (DOAS) methods in which UV/Vis (and/or IR) solar spectra are used to quantify accurately numerous chemical absorbers simultaneously (Platt, 1994). Using DOAS techniques, $\mathrm{O}_{3}$, $\mathrm{SO}_{2}, \mathrm{HCHO}, \mathrm{HONO}, \mathrm{H}_{2} \mathrm{O}, \mathrm{NO}_{2}, \mathrm{NO}_{3}, \mathrm{IO}, \mathrm{OIO}, \mathrm{OClO}$, $\mathrm{BrO}, \mathrm{O}_{4}$ and $(\mathrm{CHO})_{2}$ can be detected in the UV/Vis region. In the IR region many other species, such as $\mathrm{CO}_{2}, \mathrm{CH}_{4}, \mathrm{OIO}$, $\mathrm{H}_{2} \mathrm{O}$, and solid and liquid particles can also be observed. Additionally, cloud and aerosol light extinction coefficients can be derived from observations of the oxygen collisional dimer, $\left(\mathrm{O}_{2}\right)_{2}$, also known as $\mathrm{O}_{4}$, whose abundance is primarily dependent on atmospheric pressure (Frieß et al., 2006). The DOAS technique usually measures the difference between two spectra, a measurement and a reference, which removes spectral contributions that are common between these two spectra. In the case of solar spectra, the Fraunhofer structure is removed. The term "differential" refers to the fact that the spectral fitting exploits high-frequency variations that occur in molecular absorption spectra (typically vibronic bands) but are not present in aerosol scattering or other extinction processes that vary slowly with wavelength (for details see Platt, 1994; Platt and Stutz, 2008). This process combined with the absolute nature of the Beer-Lambert law allows for the calculation of slant column densities relative to the reference without calibration. It is important to note the distinction between passive DOAS, where scattered sunlight is used

Published by Copernicus Publications on behalf of the European Geosciences Union. 
as the light source, and active DOAS, where an artificial light source is used. The MAX-DOAS method, in which the passive DOAS technique is applied using multiple view elevations (known as axes), was first employed by Hönninger and Platt (2002) at Alert, Canada. The near-horizon view geometries used in MAX-DOAS greatly enhance the sensitivity to boundary layer species, contrasted to satellite or zenith-sky DOAS techniques, which are mostly sensitive to total column abundances (Hönninger et al., 2004). The multiple view axes of MAX-DOAS also enable trace gas vertical profiles to be derived (Hönninger et al., 2004; Wittrock et al., 2004; Heckel et al., 2005).

Low power consumption, inherent calibration, and the potential to derive vertical profiles are significant advantages of the MAX-DOAS technique; however, there are two main disadvantages to the passive DOAS technique in general. First, it can only operate during daytime or twilight hours as it requires scattered sunlight. Active DOAS techniques, where a laser (e.g. Mount, 1992), arc lamp (e.g. Platt, 1994; Platt and Stutz, 2008), or light emitting diode (LED) (Kern et al., 2006) is used as the illumination source, eliminates this problem, but often requires high power, and is therefore more difficult to employ at remote locations. The second disadvantage of passive DOAS is that obtaining chemically relevant concentration or mixing ratio values from the raw measurements is a mathematically intensive process, which lacks accepted standard procedures and has complex error estimation (e.g. Wagner et al., 2004; Frieß et al., 2006). However, satellite remote sensing techniques apply similar spectral fitting and radiative transfer methods for their analysis, so the mathematical complexity of MAX-DOAS is similar to and not worse than other remote-sensing techniques. In fact, because of similarities between ground-based passive DOAS and satellite techniques, MAX-DOAS instruments represent an important resource that can validate and improve satellite measurements (Irie et al., 2008).

The DOAS technique has been successfully adapted to ground, air, and satellite based platforms, allowing for some of the most remote locations on Earth to be studied. A prime example is detection of bromine monoxide in the polar regions. Every springtime in polar regions, reactive halogen species, including $\mathrm{BrO}$, are photochemically sourced to the atmosphere from snow and ice surfaces (Barrie et al., 1988; McConnell et al., 1992; Fan and Jacob, 1992; Tang et al., 1996; Simpson et al., 2007a). These reactive halogens are an essential reactant in tropospheric ozone depletion events (ODEs) where surface ozone levels are periodically depleted to near zero, thereby significantly altering the oxidation pathways of the atmosphere (von Glasow et al., 2004; Hönninger and Platt, 2002; Jacobi et al., 2006; Simpson et al., 2007a). Additionally, reactive halogens are believed to be the primary oxidant of gaseous elemental mercury in polar regions, leading to the deposition of reactive mercury species into the snowpack (Schroeder et al., 1998; Lindberg et al., 2002). Much of our current knowledge about tropospheric
$\mathrm{BrO}$ concentrations and spatial distribution in the polar regions comes from DOAS observations (e.g. Tuckermann et al., 1997; Hönninger and Platt, 2002; Frieß et al., 2001; Simpson et al., 2007b). Satellites such as GOME, OMI, and SCIAMACHY have for years provided pan-Arctic/Antarctic vertical column densities of $\mathrm{BrO}$ from space (Richter et al., 1998; Wagner and Platt, 1998; Wagner et al., 2001; Hollwedel et al., 2004) and passive ground based DOAS instruments have been deployed at numerous Arctic and Antarctic locations such as Alert, Canada, Spitzbergen, Svalbard and Barrow, Alaska (Kreher et al., 1997; Wittrock et al., 2000; Frieß et al., 2001; Hönninger and Platt, 2002; Simpson et al., 2007b).

As successful as these satellite and ground based DOAS instruments have been in measuring $\mathrm{BrO}$, they still possess inherent limitations. Satellites are limited by their temporal resolution (1-2 observations per day), lack stratospheric and tropospheric vertical profile information, and often do not account for cloud interferences. Also, satellite methods require ground truth observations for validation. Ground-based MAX-DOAS instruments can easily differentiate whether a gas is in the stratosphere or in the boundary-layer and can account for cloud interferences, however, many MAX-DOAS instruments use tens of watts of power and require maintenance limiting their possible deployment sites to coastal places with infrastructure, which leaves the vast majority of the polar regions unexplored. Icebreakers have been successfully used as a mobile observation platform (Wagner et al., 2007), however these ships are limited by ice conditions and are not always readily available.

In the Arctic and at many other locations around the Earth, there is a great need for automated, low power instrumentation, which is capable of continuous long-term atmospheric monitoring. A number of miniaturized ground-based passive DOAS instruments have been recently developed. These instruments are smaller, use less power, and easier to use that previous instruments, however they still lack sufficient automation for long-term remote deployment. The Flyspec and Mini-DOAS instruments have been developed to quantify $\mathrm{SO}_{2}$ emissions from volcanoes (Horton et al., 2006; Galle et al., 2002) and are a significant improvement from the now outdated COSPEC instrument (Moffat and Millan, 1971). However, the view telescope on some of these instruments must be manually moved to each different view axis, requiring a person to always be present during operation. Other DOAS instruments, such as in Hönninger et al. (2004) and Wittrock et al. (2004), use a stepper motor to automate changes in view direction, however, there is still a lack of automated instrumental quality checks to ensure proper functioning during remote long-term deployment. These instruments also have a higher than desirable total power consumption due to use of Peltier-effect cooling devices or resistive heating elements to stabilize the spectrometer temperature. 


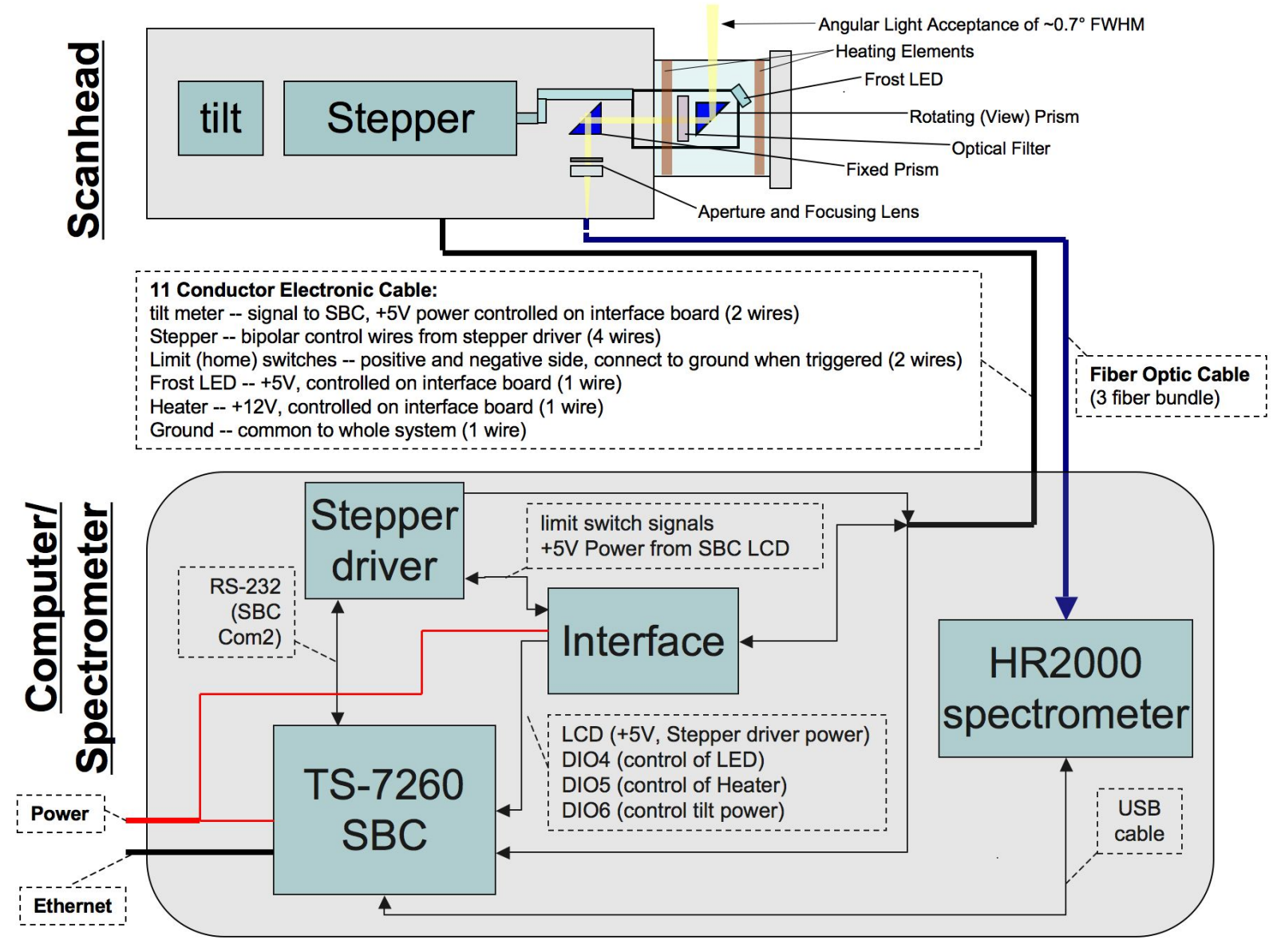

Fig. 1. Schematic of new MAX-DOAS system. The scan head (top) is connected to the computer/spectrometer (bottom) by a fiber optic cable and electronic cable.

To increase data collection of trace gases in the Arctic, and at other remote locations such as volcanoes, we have developed a new MAX-DOAS system that is low-power $(<3 \mathrm{~W})$, automated, and field deployable. Design features include: a separate, fully enclosed weatherproof optical scan head, frost detection and removal capability on the view window, integrated tilt meter to ensure correct view elevation angle, passively temperature-stabilized spectrometer, continually updated dark current and offset corrections to the spectrometer, fully automated data acquisition software, and compatibility with two-way satellite and ethernet communication devices.

\section{Instrument}

A schematic of the overall instrument setup is shown in Fig. 1. There are two sub-systems, the scan head, which receives the scattered sunlight, and the spectrometer/computer unit, which runs the system and detects and stores the spectral data. The two sub-systems are linked by a UV/Vis fused silica fiber optic cable and a multi-conductor electronic cable.

\subsection{Scan head sub-system}

The scan head sub-system, shown in Fig. 2, is contained in a sealed aluminum housing with a cylindrical quartz window through which scattered sunlight is viewed. The housing is made airtight by sealing all unions with O-rings and using airtight glands and connectors for the electronic cable and fiber optic cable. This enclosed design protects internal optics and moving parts from physical obstruction or weathering and is important for successful long-term operation in the Arctic. Most previous MAX-DOAS instruments have external moving parts which are subject to weathering and obstruction (Hönninger et al., 2004; Horton et al., 2006; Galle et al., 2002) Scattered sunlight is directed through the system using a set of two right angle fused silica prisms (Optics For Research, ADU-15 mm), where the outer prism is rotated about the axis between the two in order to obtain light from different view elevations. This design allows a scanning range of approximately $220^{\circ}$, from slightly below the horizon, up and over the zenith, and through the horizon on the opposite side. 


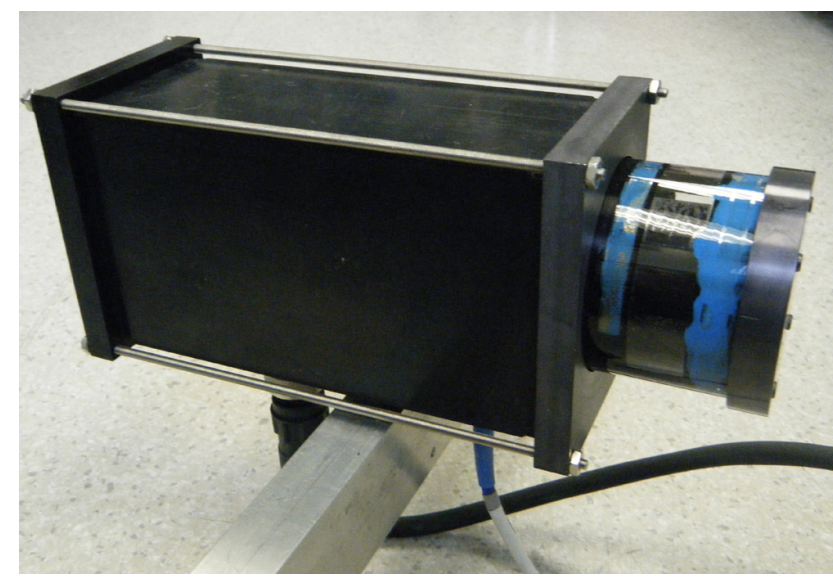

Fig. 2. A photograph of the scan head. The view window is the clear quartz region between two defroster heaters that appear blue due to the blue thermally conductive epoxy glue.

Between the two prisms is a Schott BG3 bandpass optical filter (UV-VIS bandpass approximately $315-445 \mathrm{~nm}$ ). The filter excludes light of wavelengths that are not in the region of interest and reduces the possibility for light to be scattered within the spectrometer, which could contribute to instrumental artifacts. From the second, i.e. non-rotating prism, the light passes through an $f$-stop $(f / 4)$ and a fused silica lens (Thorlabs, LA4936-UV, 30mm focal length) that focuses the light into the entrance of the fiber optic cable. The fused silica lens is adjusted until the instrumental field of view is between $0.5^{\circ}$ and $1^{\circ}$. A range is reported because the field of view varies slightly with wavelength due to the lens's chromatic aberration. The fiber optic cable (Ocean Optics) is a three-fiber armored bundle with a triangular configuration on the scan head end, and a linear slit arrangement for the spectrometer entrance end. Each of the three fibers is $200 \mu \mathrm{m}$ in diameter and 0.22 numerical aperture.

\subsection{Determination of view elevation angle}

A geared stepper motor (Oriental Motors, PK223PA-SG36, $0.05^{\circ}$ per step) rotates the movable prism to achieve different view elevation angles. Two limit switches are used to calibrate the prism orientation with respect to the scan head. The algorithm for determining the optical position takes into account the $\sim 1^{\circ}$ freeplay in the gear mechanism. To determine the telescope orientation with respect to the horizon, a tilt meter (SmartTool Technologies ISU-S, $+/-0.1^{\circ}$ accuracy and $0.01^{\circ}$ reported resolution) is mounted in the scan head and is used to convert the scan head based orientation into a true horizon oriented coordinate system.

\subsection{Frost detection and removal}

Snow or frost buildup on the optical input window can be particularly problematic in polar regions. For this reason, this new MAX-DOAS system is equipped with a frost detection

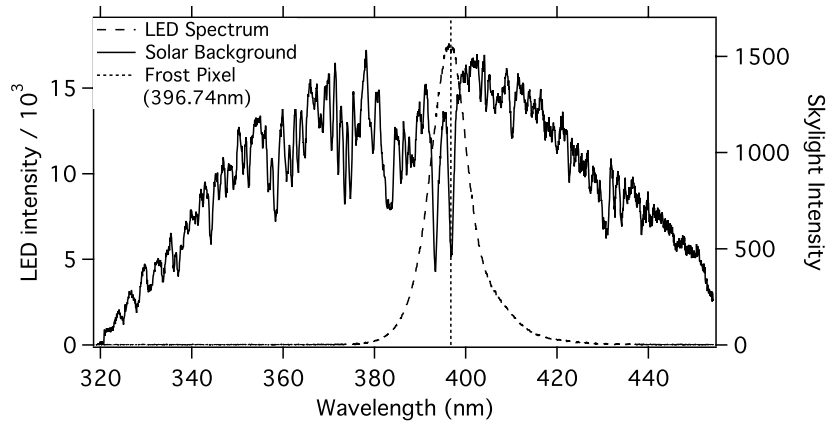

Fig. 3. Frost detection scheme example spectra. The dashed line shows the spectrum of the frost detection LED, while the solid line is an observed skylight spectrum. The frost detection wavelength, $396.7 \mathrm{~nm}$, is chosen to be at the base of the Fraunhofer dip to minimize skylight interference in the frost measurement.

and window heating system, which ensures a clear instrumental view while conserving power by not heating the window when it is not needed. A near-UV LED $(\sim 397 \mathrm{~nm})$ is used to illuminate the view window at an oblique angle, and the telescope/spectrometer receives this light when the window is frosted. The oblique illumination nearly eliminates scattering of LED light into the telescope when the window is clear. Daylight signals are removed by subtracting the intensity with the LED off from the LED on scattered light signal, as shown in Fig. 3. The wavelength chosen for observation $(396.7 \mathrm{~nm})$ is in a large Fraunhofer dip to reduce the effect of ambient skylight while being near the emission maximum of the LED. Frost counts are measured and logged each time the view prism is rotated to a new view elevation angle.

When the frost signal exceeds a pre-set threshold, two small resistive heating elements $(39 \Omega$ total, $3.75 \mathrm{~W}$ at $12 \mathrm{~V}$, Minco, HK5205R76.5L 12 A) are turned on. These heaters are glued to the inside of the quartz window (see Fig. 1) using thermally conductive epoxy. In addition to the heaters, the inside of the quartz cylinder is painted black everywhere except at the viewing directions so that passive solar heating is maximized. Previous MAX-DOAS instruments have not been capable of detecting and removing frost and instead required on continual human maintenance to ensure a clear instrument view and high quality data (Hönninger et al., 2004; Horton et al., 2006; Galle et al., 2002; Wittrock et al., 2004)

\subsection{Dark current and offset corrections to the spectrometer}

Each recorded spectrum is the sum of the measured skylight intensity, an electronic offset applied by the spectrometer, and time-accumulated thermal or dark current. Therefore, offset and dark current spectra must be subtracted from all measurement spectra to give signals directly proportional to light intensity. Since the offset and dark current can vary with time, new correction spectra must be periodically 

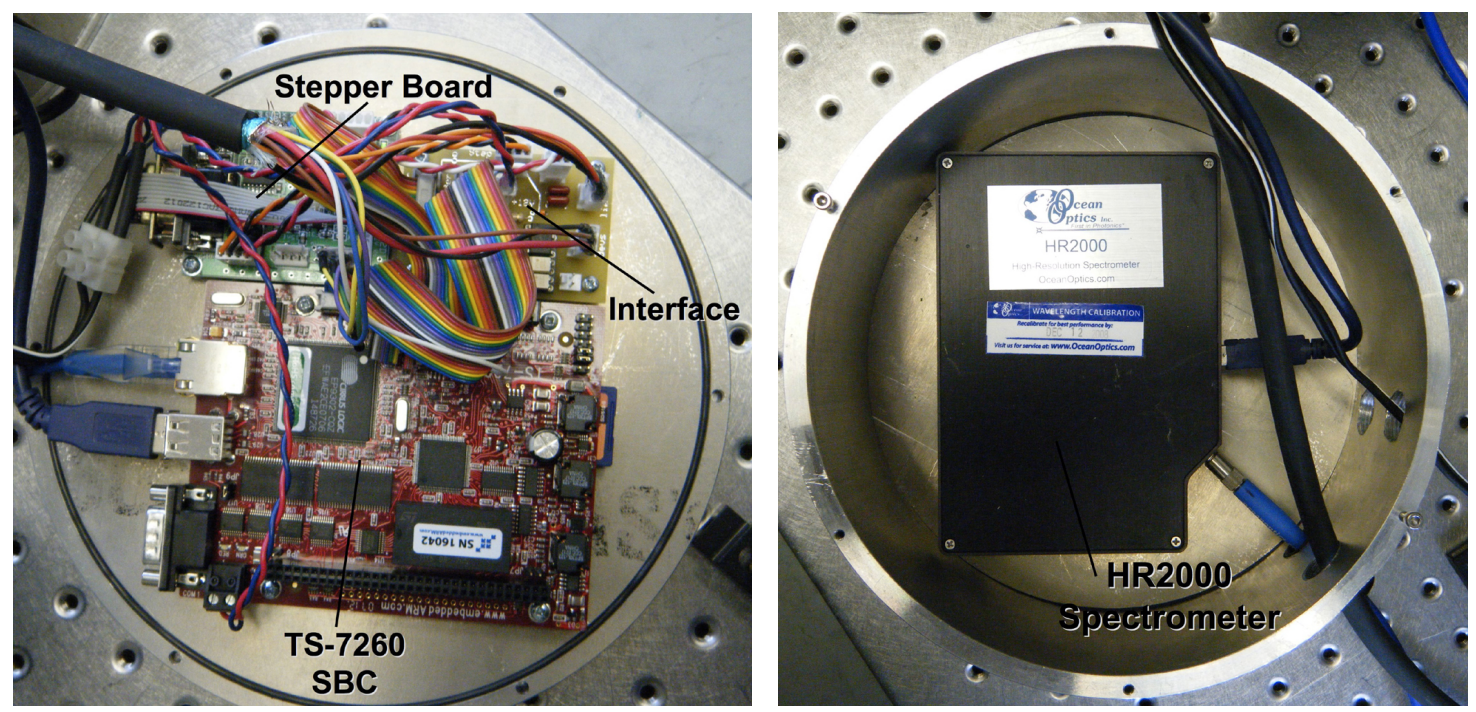

Fig. 4. The computer/spectrometer subsystem. In left panel is the top of the housing, where we have mounted the single-board computer (SBC), stepper motor driver, and interface circuit boards. The right panel shows the Ocean Optics HR2000 spectrometer thermally contacted to the aluminum housing base.

acquired. Two pieces of black, light absorbing photography paper cover the instrument window at two unused view elevation angles, approximately $30^{\circ}$ from the zenith. To obtain new dark current and offset spectra, the view prism is oriented at the black paper and spectra are recorded with short and long exposure times. While scattered sunlight is not completely eliminated by the dark paper, it is reduced to the extent that dark current and offset correction spectra can be extracted.

\subsection{Spectrometer/computer sub-system}

The second sub-system consists of a single-board computer (SBC), a spectrometer, a stepper motor driver circuit board, and a signal routing interface circuit board as pictured in Fig. 4. The spectrometer is an Ocean Optics HR2000. This spectrometer model has been successfully used for DOAS studies in the past (Weidner et al., 2005) The spectral resolution is $0.65 \mathrm{~nm}$ full width at half maximum as determined by observation of the $334 \mathrm{~nm}$ mercury atomic emission line, which has a roughly Gaussian line shape with apparent leftright symmetry. The $334 \mathrm{~nm}$ emission line is within our wavelength region of interest, $334 \mathrm{~nm}-360 \mathrm{~nm}$, and yields a useful instrument slit function to be used during the spectral fitting procedure (Sect. 4.4). The spectrometer wavelength range, $318-455 \mathrm{~nm}$, allows for detection of chemical species with absorption features in the UV wavelengths as well as the violet and blue regions of the visible spectrum, including $\mathrm{O}_{3}$, $\mathrm{BrO}, \mathrm{OClO}, \mathrm{HCHO}, \mathrm{HONO}, \mathrm{H}_{2} \mathrm{O}, \mathrm{NO}_{2}, \mathrm{IO}, \mathrm{O}_{4}$ and $(\mathrm{CHO})_{2}$. Shifting this spectral window to the UV would allow the instrument to detect $\mathrm{SO}_{2}$ and $\mathrm{ClO}$. The HR2000 spectrometer is extremely low power (about $0.5 \mathrm{~W}$ ), compared to other models with similar specifications, and is also relatively inexpensive ( $\sim 3400$ USD).

Since the detector's wavelength-to-pixel relationship is sensitive to changes in temperature, the spectrometer is thermally contacted to the bottom of the aluminum housing. The aluminum housing can subsequently be thermally regulated by placing it in good thermal contact with a large heat sink, such as below the active layer of soil or in a large body of water. Placing the aluminum housing in thermal contact with Arctic Ocean sea water has proven effective in stabilizing the temperature to within less than $1{ }^{\circ} \mathrm{C}$ on short timescales (the time between observation low elevation spectra and zenith spectra) and a few ${ }^{\circ} \mathrm{C}$ on month to year timescales. Alternatively, if power is locally available the spectrometer temperature can be controlled by an electric heater and thermostat device. The spectral drift of the HR2000 spectrometer as a function of temperature was measured in the laboratory and found to be roughly $0.01 \mathrm{~nm} /{ }^{\circ} \mathrm{C}$ in the 346 to $364 \mathrm{~nm}$ wavelength region.

The single-board computer is a Technologic Systems TS7260 running linux, which is connected to the spectrometer using USB and to other peripherals using RS-232 ports and digital I/O. The computer is networked using Ethernet. The stepper motor driver (BC2D15-RS232, Peter Norberg Consulting) fires the motor windings at a specified speed and direction, and also receives the limit switch signals. The single-board computer controls the stepper motor driver using a serial (RS-232) port. An interface circuit board contains three solid-state relays (SSRs) to control power to the window heater, frost sensor LED, and tilt meter. Digital I/O on the computer control these SSRs to conserve power by turning the devices off when not needed. The tilt meter reports 
the tilt angle over a serial (RS-232) port on the single-board computer and is powered off in between tilt measurements to save power.

\section{Instrument operations}

This instrument operates remotely without any maintenance. The main data acquisition program, which is executed on boot of the SBC, automatically records scattered light spectra at a series of elevation angles while simultaneously monitoring and correcting for varying instrument and environmental conditions.

\subsection{Scan pattern}

The instrument repetitively scans the telescope between a series of elevation angles (typically $2^{\circ}, 5^{\circ}, 10^{\circ}, 20^{\circ}$, and $90^{\circ}$ elevation from the horizon). An automatic algorithm optimizes the exposure time (typically $0.1-0.4 \mathrm{~s}$ for sunny conditions), and spectra are coadded for a short integration interval (typically 60-90 s) before advancing to the next elevation angle in the sequence. The elevation angle sequence is then repeated until the recording interval (typically about $30 \mathrm{~min}$ ) is exceeded. The coadded spectra at each elevation angle, along with ancillary data, are then written into a data record. This record represents the inherent time resolution in this mode of operation and is set based upon a compromise between time resolution and file transfer size. The scan pattern is repeated multiple times in a single record so that short-term variability in clouds or other optical properties are averaged over. Dark and offset spectra are observed at the end of the scan pattern by rotating the telescope to the elevation of the dark blocker.

\subsection{Communications and data retrieval}

At high-infrastructure locations, the SBC can report the data over the internet using automatic data transfers to a secure ftp site, and the instrument can be monitored and its operations modified over the internet. For more remote sites, the SBC can be connected to an iridium satellite transmitter/receiver, which is also capable of automatic data transfers and twoway communications (Knepp et al., 2010). Protocols for reprogramming the SBC have been established and we have successfully uploaded new versions of the operational software and parameters remotely.

\subsection{Instrument function monitoring}

Each time that the stepper motor is returned to a limit switch, the step angle is recorded as a check that the motor is not losing steps. The angle counter is then reset to the limit switch's position value. Under normal operating conditions the homing error is very low, with an RMS deviation of $0.015^{\circ}$ over a 3 month operational period. In addition to using the tilt meter in the scan head to automatically adjust the telescope's position, the tilt meter's reading is recorded to verify proper operation of the sensor and identify if the instrument has been tilted (for example by shifting sea ice or disturbance by Polar Bears). The average frost signals at each elevation angle are also written into the data record.

\section{Instrument performance}

\subsection{Light intensity at different view angles}

To test the instrument's response at different view elevations, a fixed broadband light source (an unfiltered halogen lamp) was observed at a variety of positions between the two horizons. This was accomplished by manually rotating the entire scan head about its longitudinal axis, while rotating the view prism in the opposite direction by the stepper motor to observe transmitted light through a Lambertian diffuser (a back-illuminated Teflon sheet). The Teflon was mounted $50 \mathrm{~cm}$ from the scan head, and could be observed over an aperture of roughly $10^{\circ}$. Figure 5 panel A shows the instrumental response as a function of scan head angle. Data points represent the average of six measured spectra at each angle and are shown for two distinct spectral ranges, 360-364 nm and $420-430 \mathrm{~nm}$. Standard deviations of the intensities at each angle are less than one percent. Each angle showed similar average intensities, with the standard deviation of $1 \%$ between the angles. This observation indicates that the instrument has a uniform response to light intensity at all scan head view angles.

\subsection{Polarization effects}

Spectrometers generally have differing sensitivity to different polarization states of incoming light. Because scattered sunlight is polarized, it is necessary to understand the instrument's sensitivity to polarized light for accurate analysis of the MAX-DOAS signals. For this instrument, we attempt to equalize the sensitivity to horizontal and vertical polarization by using the fiber optic cable to randomize the polarization. To test the polarization sensitivity, we modified the above procedure by adding a polarized sheet between the scan head and light source. At each scan head angle five spectra were recorded with the polarization filter oriented horizontally, and then five with the filter oriented vertically. Each horizontally filtered spectrum was subtracted from the average of all the vertically filtered spectra at the same scan head angle and divided by the average intensity of all (both horizontally and vertically filtered) spectra to give the percent residual polarization sensitivity. The converse method, subtracting the average of the horizontally filtered spectra from each vertically filtered spectrum and then dividing by average of all spectra, is used to calculate percent differences for the individual vertically filtered spectra. This procedure results in ten observations of the polarization sensitivity defined by $(\mathrm{V}-\mathrm{H}) /(\mathrm{V}+\mathrm{H}) / 2$. Plots B and C of Fig. 5 shows average and 


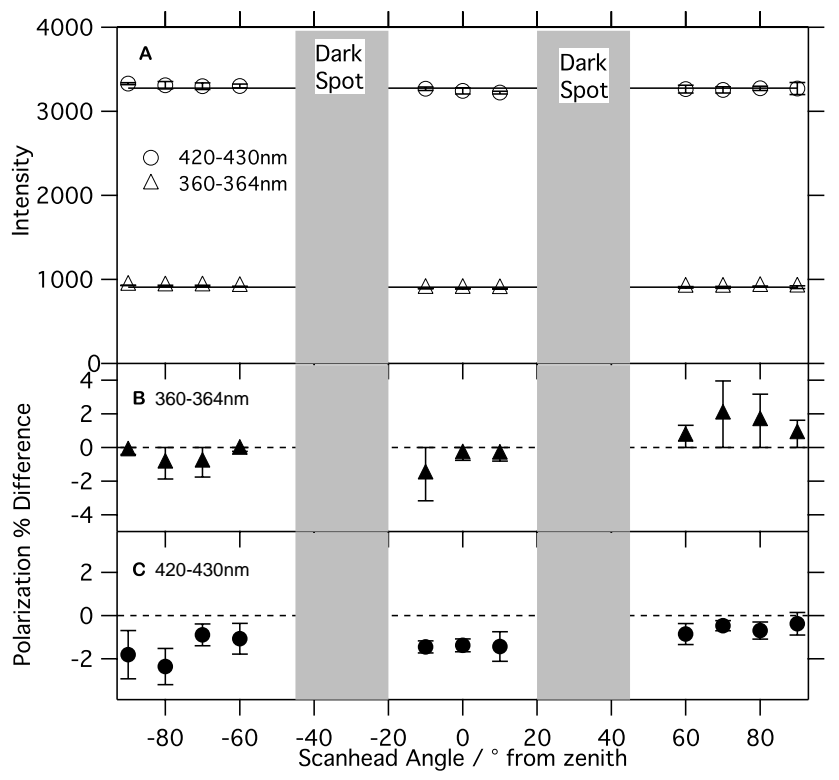

Fig. 5. Instrumental characterization. Panel A demonstrates constant light intensity observed at different scan head view angles over two different wavelength regions (420-430 $\mathrm{nm}$ and 360-364 nm). These data points are the average of six different spectra and show standard deviations $(1 \sigma)$ of less than one percent. Panels $\mathbf{B}$ and $\mathbf{C}$ show the average percent difference, $100 \% *(\mathrm{~V}-\mathrm{H}) /(\mathrm{H}+\mathrm{V}) / 2$, with $+/-1 \sigma$ error bars in intensity between horizontally and vertically polarization-filtered light. The small percent differences indicate that the system is minimally biased by polarized light.

standard deviations $(1 \sigma)$ of the residual polarization sensitivity, in percent. In Fig. 5, panel B (360-364 nm) the observed small percent differences $(<+/-3 \%)$ and the error bars overlap zero indicating that the instrument has no polarization sensitivity in this wavelength region. At longer wavelengths, as shown in Fig. 5, panel C $(420-430 \mathrm{~nm})$ the percent differences are consistently about $1 \%$ below zero and the error bars are small enough that they generally do not overlap zero. It is possible that the fiber optic cable is not long enough to scramble completely the polarized light at these wavelengths. If, for another application, the current depolarization performance was inadequate, a depolarizer could be added at the expense of slight optical transmission loss. However, this spectrometer bias to polarized light is around $1 \%$ and would not be expected have a large impact on spectral fitting results. Also, as noted below in Sect. 4.4 the spectral fitting window used for quantification of $\mathrm{BrO}$ is much closer to the 360-364 nm region shown in Fig. 5, panel B.

\subsection{Power budget}

This instrument is designed for long-term automated data acquisition; therefore, it is essential to evaluate the power usage, so that sufficient power can be allocated to run the instrument for the duration of a projected campaign. The
Table 1. The power budget of the MAX-DOAS instrument measured in the laboratory at $12 \mathrm{~V} \mathrm{DC}$. The weighted power is the product of the duty cycle and the power consumption of each component. The window heater is not included in the total power consumption because its duty cycle varies strongly with weather conditions.

\begin{tabular}{lrrrr}
\hline Component & $\begin{array}{r}\text { Current } \\
(\mathrm{A})\end{array}$ & $\begin{array}{r}\text { Power } \\
(\mathrm{W})\end{array}$ & $\begin{array}{r}\text { Duty } \\
\text { cycle }\end{array}$ & $\begin{array}{r}\text { Weighted } \\
\text { Power }(\mathrm{W})\end{array}$ \\
\hline Computer & 0.11 & 1.26 & 1.00 & 1.26 \\
Stepper motor & 0.08 & 0.90 & 1.00 & 0.90 \\
Driver electronics & & & & \\
Spectrometer & 0.05 & 0.54 & 1.00 & 0.54 \\
Motor (moving) & 0.11 & 1.32 & 0.01 & 0.01 \\
Frost LED & 0.03 & 0.36 & 0.01 & $<0.01$ \\
Window Heater & 0.31 & 3.72 & variable & variable \\
\cline { 2 - 5 } & \multicolumn{2}{c}{ Total Power Consumption: } & 2.71 \\
\hline
\end{tabular}

power consumption (at $12 \mathrm{~V}$ ) and duty cycle of each individual component was measured in the laboratory and are listed in Table 1. The computer, stepper driver electronics, and spectrometer always draw current (duty cycle of 1 ) and establish a baseline instrument power consumption of $2.7 \mathrm{~W}$. The other system components do not significantly contribute to the long-term power consumption due to the low duty cycle; however, they can cause large momentary spikes in the power consumption. For example, the stepper motor only moves for about $1 \%$ of the operational time, but when it does, it adds $1.3 \mathrm{~W}$, bringing the total power consumption at that moment to $4.0 \mathrm{~W}$. If both the window heater and the motor are simultaneously drawing current, the power consumption spikes up to the maximum power consumption, $7.7 \mathrm{~W}$.

The duty cycle of the window heater is the biggest unknown in the power budget because the amount of heating required to keep the window free of frost is highly variable and depends on humidity, ambient temperature, wind, and amount of passive solar heating to the window. If frost is absent, the heater has a zero duty cycle and does not consume any power. If the window is frosted and it takes $2 \mathrm{~h}$ per day of heating to keep the window clear, then the duty cycle is $2 \mathrm{~h} / 24 \mathrm{~h}$ (or 0.08 ), adding an average of $0.3 \mathrm{~W}$ to the average operational power consumption, bringing the total to $3.0 \mathrm{~W}$. Snow buildup on the window takes longer to heat off than vapor deposited frost; however, wind and the curved shape of the quartz window usually prevent snow accumulation. The maximum operational time of the MAX-DOAS instrument will vary widely depending on the total battery capacity, use of solar power, and how often the instrument is turned on, but it is possible that with proper power allocation an instrument can operate for over a year on the original power supply. 


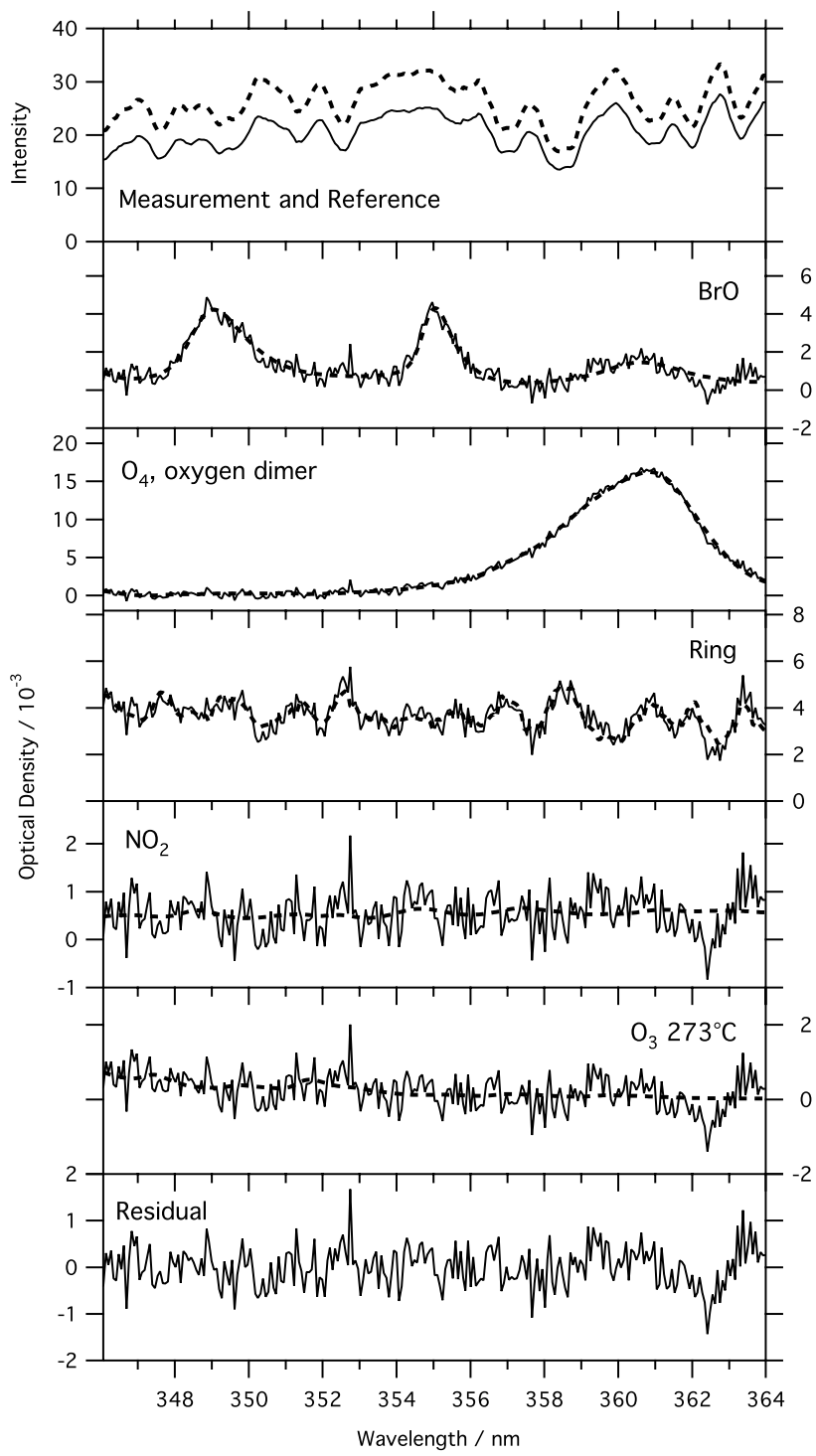

Fig. 6. Example of a spectral fit from Barrow, Alaska on 18 March 2009. The view elevation angle is $2^{\circ}$ above the horizon and solar zenith angle (SZA) is $74^{\circ}$. In each panel, the solid line is the measurement spectrum and dotted line is the modeled partial fit, or the reference spectrum in the case of the top plot. The observed differential slant column densities (which are the fit coefficients) are as follows: BrO: $4.96 \times 10^{14}$ molecules $/ \mathrm{cm}^{2}$, $\mathrm{O}_{4}: 3.83 \times 10^{43}$ molecules $2 / \mathrm{cm}^{5}, \mathrm{NO}_{2}: 1.17 \times 10^{15}$ molecules $/ \mathrm{cm}^{2}$, $\mathrm{O}_{3}$ at $273 \mathrm{~K}: 1.62 \times 10^{18}$ molecules/ $/ \mathrm{cm}^{2}$. The RMS deviation of the residual spectrum from zero is $4.40 \times 10^{-4}$.

\subsection{Spectral fitting}

In the MAX-DOAS method, each measurement spectrum is referenced to a corresponding local (meaning at nearly the same time) zenith reference spectrum. The details of this fitting procedure as well as results from using a single fixed solar reference spectrum are given in Donohoue et al. (2010). The molecular absorption cross-sections used are
Wilmouth et al. (1999) for BrO, Vandaele et al. (1998) for $\mathrm{NO}_{2}$, Hermans et al. (2001) for $\mathrm{O}_{4}$, and Bogumil (2000) for $\mathrm{O}_{3}$. For $\mathrm{BrO}$, the foundation of the spectral fitting procedure was the recommendations put forth in Aliwell et al. (2002), with some modification including the use of updated crosssection data and the extension of the fit window to $364 \mathrm{~nm}$. These modifications improve our selectivity for $\mathrm{BrO}$ and allow more accurate $\mathrm{O}_{4}$ measurements. In addition, since we use a local zenith spectrum as the reference the influence of stratospheric ozone is limited. Therefore, only one ozone cross-section in necessary to characterize the ozone, rather than the two ozone cross-section recommended by Aliwell et al. (2002). We performed an initial wavelength calibration using the emission lines of a mercury vapor lamp. This initial wavelength calibration is then refined by fitting the Fraunhofer dip features of a high-resolution solar spectrum for each local zenith spectrum. The required wavelength shifts are typically less than $+/-0.01 \mathrm{~nm}$, and fall in this range on the data shown in Fig. 6. The wavelength-calibrated spectra are fit in the 346-364 nm window to molecular reference spectra using QDOAS spectral fitting software (http://uv-vis. aeronomie.be/software/QDOAS/). All molecular reference spectra are convoluted using an instrumental slit function determined from the $334 \mathrm{~nm}$ mercury emission line from a calibration spectrum that is recorded in the field at time of deployment. The QDOAS software calculates differential slant column densities (dSCD) as shown in Fig. 6. A third-order polynomial and a first-order offset spectrum (not shown) are also fit to the spectral data to account for slowly varying aerosol absorptions and instrumental effects, respectively.

This spectral fitting procedure was used to analyze data from Barrow, Alaska during Spring of 2009, when the instrument was tested on the O-buoy platform (Knepp et al., 2010). The maximum BrO dSCD observed during this time period was $6 \times 10^{14}$ molecules $/ \mathrm{cm}^{2}$. Figure 7 shows an example of data for the day of 18 March 2009 AKST using the above spectral fitting procedure. On this day, the early hours of observations are affected by frost accumulation, as indicated on the middle panel. When the frost signal is above the operational threshold, the plot is shaded grey. It is noticeable that when frost counts are high the dSCD values for all view elevation angles converge to near-zero values. This effect arises from the fact that frost scatters photons from all different directions into the telescope, making no difference in the spectra taken at nominally different elevation angles. After the frost is heated off the window, a pattern of higher dSCDs at lower elevation angles emerges, which indicates that $\mathrm{BrO}$ is near the ground surface. During the middle of the day the $\mathrm{BrO} \mathrm{dSCD}$ at low elevation reaches $5 \times 10^{14}$ molecules $/ \mathrm{cm}^{2}$ at the $2^{\circ}$ elevation angle, indicating significant halogen activation in the boundary layer. Analysis of the BrO dSCD as a function of view elevation angle utilizing a radiation-transfer model allows derivation of the vertical profile of $\mathrm{BrO}$, as described in Donohoue et al. (2010). The average RMS fit error for spectra with SZAs less than $<80^{\circ}$ is $5.4 \times 10^{-4}$, which 


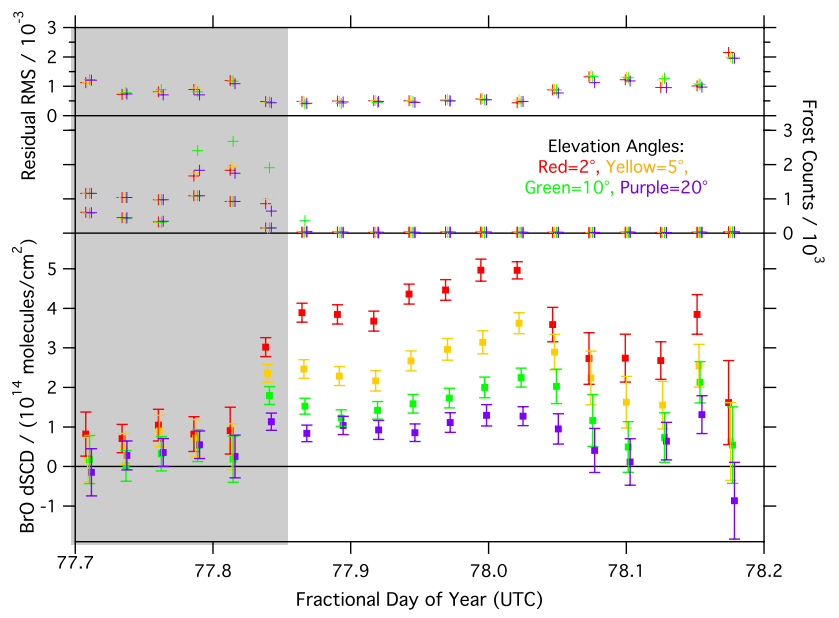

Fig. 7. MAX-DOAS observations on 18 March 2009 in Barrow, AK (fractional day of year 77.7-78.2 UTC). Top: Spectral fit residual RMS values. Middle: Frost count values. Bottom: local zenith referenced dSCD values of $\mathrm{BrO}$ with spectral fitting error bars. Frost on the instrument view window (times shaded in grey) causes the $\mathrm{BrO}$ dSCDs at all view elevation angles to be zero. Average midday RMS values (SZA less than $80^{\circ}$ ) are $5.4 \times 10^{-4}$.

is typical for this instrument and attests to the spectral data quality. These data are analyzed using local zenith reference spectra, giving sensitivity to boundary-layer absorbers. However, fitting the spectra with a single (typically a zenith spectrum at solar noon) reference spectrum provides a means to quantify the stratospheric $\mathrm{BrO}$ vertical column abundance (e.g. see Aliwell et al., 2002 and Donohoue et al., 2010).

\section{Possible design modifications}

Prospects for future instrument modification include making further power reductions, and exploring different scan head designs. While the instrument power consumption is already quite low, it would be possible to further reduce power consumption of the stepper motor driver by using more efficient electrical components and by turning off power to the driver electronics when not in immediate use. Also, small computers with even lower power consumption may be available. The use of Seebeck elements could possibly help to power the instrument by exploiting an environmental temperature difference, for example warm sea water and cold arctic air. While the clinometer in the scan head housing is sufficient for measuring instrument tilt, it is more desirable to have a clinometer attached to the rotating prism mount itself to obtain a more direct measure of the view elevation angle. Another change to the scan head might be to reduce the size of the quartz viewing window, which would give similarly powered heaters a higher power density and facilitate frost removal. The scan head design could even be changed to eliminate the cylindrical window entirely, in which case the view prism tube would protrude through the front plate of the scan head and would be sealed with a rotary seal. This design would differ from the original intention of having no external moving parts; however, it would have the benefit of being able to face the view prism downward when not in use, to avoid snow or dirt accumulation. Testing would be required to determine the longevity and friction of the rotary seal, particularly at very low temperatures.

\section{Discussion/conclusions}

MAX-DOAS observations have the potential to contribute to our understanding of reactive trace gases through collaborative chemical process studies in which the relationships between multiple chemical compounds are explored and chemical mechanisms and models are tested and improved. Additionally MAX-DOAS can help validate and refine satellite observations so that our mechanistic understanding can be extrapolated to the global scale. The new features of this instrument expand the applicability of the MAX-DOAS method to include long-term data collection at remote unmanned locations. The low power demand allows the possibility to run the entire system using battery, solar, or wind power. The automated and self-correcting instrument checks ensure that all data is taken from the intended view direction and with a clear view path. Resulting spectra are of high quality and allow derivation of meaningful trace gas slant column densities and vertical profiles. The two-way communications allow for continuous monitoring and data retrieval, making real time data analysis a possibility. This instrument has recently been integrated into a chemical measurement ice tethered buoy. In the next few years these buoys will be distributed around the Arctic, providing year round trace gas data from remote sea ice locations. For more information on the O-buoy platform see Knepp et al. (2010).

While this instrument was originally developed for use in the polar regions, it is also very well suited to volcanic sites and other remote locations. Volcanoes have been shown to emit many chemically important species such as $\mathrm{BrO}$ and $\mathrm{SO}_{2}$ (Bobrowski, 2003). However, the global contributions and effects of the reactive gases released by volcanoes are not accurately known. The logistical challenges of studying volcanic gases include lack of easy access, lack of power, settling of ash on instrumentation, and the ever-present danger of harmful out gassing or violent eruption. The automation, low power consumption, and two-way communications of this MAX-DOAS instrument make it well suited to volcano studies. Additionally, any ash or debris on the window would be detected by the frost detector and any movement of the instrument would be detected and accounted for by the tilt meter. 
Acknowledgements. This work was supported by the National Science Foundation under grant (ARC-0612457). We thank the Barrow Arctic Science Consortium (BASC) for logistical support. We also thank our fellow collaborators in the O-buoy project (see Knepp et al., 2010), particularly Todd Valentic, who greatly assisted in computer design and techniques for remote operations of this instrument. We also thank Zachary Plovanic for assistance in programming the single-board computer. Zachary's work was supported in part by a grant of HPC resources from the Arctic Region Supercomputing Center at the University of Alaska Fairbanks as part of the Department of Defense High Performance Computing Modernization Program.

Edited by: J.-B. Renard

\section{References}

Barrie, L. A., Bottenheim, J. W., Schnell, R. C., Crutzen, P. J., and Rasmussen, R. A.: Ozone destruction and photochemical reactions at polar sunrise in the lower Arctic atmosphere, Nature, 334, 138-141, 1988.

Bobrowski, N., Hönninger, G., Galle, B., and Platt, U.: Detection of bromine monoxide in a volcanic plume, Nature, 423, 273-276, 2003.

Bogumil, K.: Temperature dependent absorption cross sections measured with the SCIAMACHY satellite spectrometer, http: //www.iup.uni-bremen.de/gruppen/molspec/SCIA.html, last access: March 2010, 2000.

Donohoue, D., Carlson, D., and Simpson, W. R.: Inversion of MAX-DOAS elevation profiles to boundary layer box concentrations, visibility, and heights: Application to analysis of Arctic $\mathrm{BrO}$ events, in preparation, 2010.

Dobson, G. M. B. and Harrison, D. N.: Measurements of the amount of ozone in the Earth's Atmosphere and its Relation to other Geophysical Conditions, Proc. R. Soc. London, 110, 660693, 1926.

Fan, S.-M. and Jacob, D. J.: Surface ozone depletion in Arctic spring sustained by bromine reactions on aerosols, Nature, 359, 522-524, 1992.

Frieß, U., Wagner, T., Pundt, I., Pfeilsticker, K., and Platt, U.: Spectroscopic measurements of tropospheric Iodine oxide at Neumayer station, Antarctica, Geophys. Res. Lett., 28, 1941-1944, 2001.

Frieß, U., Monks, P. S., Remedios, J. J., Rozanov, A., Sinreich, R., Wagner, T., and Platt, U.: MAX-DOAS $\mathrm{O}_{4}$ measurements: A new technique to derive information on atmospheric aerosols: 2.Modeling studies, J. Geophys. Res., 111, D14203, doi:10.1029/2005JD006618, 2006.

Galle, B., Oppenheimer, C., Geyer, A., McGonigle, A., Edmonds, M., and Horrocks, L.: A miniaturised ultraviolet spectrometer for remote sensing of $\mathrm{SO}_{2}$ Fluxes: A new tool for volcano surveillance, J. Volcanol. Geotherm. Res., 119, 214-254, 2002.

Heckel, A., Richter, A., Tarsu, T., Wittrock, F., Hak, C., Pundt, I., Junkermann, W., and Burrows, J. P.: MAX-DOAS measurements of formaldehyde in the Po-Valley, Atmos. Chem. Phys., 5, 909918, 2005,

http://www.atmos-chem-phys.net/5/909/2005/.
Hermans, C., Vandaele, A. C., Coquart, B., Jenouvrier, A., Merienne, M. F., Fally, S., Carleer, M., and Colin, R., Absorption bands of $\mathrm{O} 2$ and its collision-induced bands in the 30000$7500 \mathrm{~cm}^{-1}$ wavenumber region, in: IRS 2000: Current Problems in Atmospheric Radiation, edited by: Smith, W. L. and Timofeyev, Y. M., A. Deepak, Hampton, VA, 639-642, 2001.

Hollwedel, J., Wenig, M., Beirle, S., Kraus, S., Kühl, S., WilmsGrabe, W., Platt, U., and Wagner, T.: Year-to- Year Variability of Polar Tropospheric BrO as seen by GOME, Adv. Space Res., 34, 804-808, 2004.

Hönninger, G. and Platt, U.: Observations of $\mathrm{BrO}$ and its vertical distribution during surface ozone depletion at Alert, Atmos. Environ., 36, 2481-2490, 2002.

Hönninger, G., von Friedeburg, C., and Platt, U.: Multi axis differential optical absorption spectroscopy (MAX-DOAS), Atmos. Chem. Phys., 4, 231-254, 2004, http://www.atmos-chem-phys.net/4/231/2004/.

Horton, K. A., Williams-Jones, G., Garbeil, H., Elias, T., Sutton, A. J., Mouginis-Mark, P., Porter, J. N., and Clegg, S.: Real-time measurement of volcanic $\mathrm{SO}_{2}$ emissions: validation of a new UV correlation spectrometer (FLYSPEC), Bull. Volcanol., 68(4), 323-327, 2006.

Irie, H., Kanaya, Y., Akimoto, H., Tanimoto, H., Wang, Z., Gleason, J. F., and Bucsela, E. J.: Validation of OMI tropospheric $\mathrm{NO}_{2}$ column data using MAX-DOAS measurements deep inside the North China Plain in June 2006: Mount Tai Experiment 2006, Atmos. Chem. Phys., 8, 6577-6586, 2008, http://www.atmos-chem-phys.net/8/6577/2008/.

Jacobi, H.-W., Kaleschke, L., Richter, A., Rozanov, A., and Burrows, J. P.: Observation of a fast ozone loss over frost flowers in the marginal ice zone of the Arctic Ocean, J. Geophys. Res., 111, D15309, doi:10.1029/2005JD006715, 2006.

Kern, C., Trick, S., Rippel, B., and Platt, U., Applicability of lightemitting diodes as light sources for active DOAS measurements, Appl. Optics, 45, 2077-2088, 2006.

Knepp, T. N., Bottenheim, J., Carlsen, M., Carlson, D., Donohoue, D., Friederich, G., Matrai, P. A., Netcheva, S., Perovich, D. K., Santini, R., Shepson, P. B., Simpson, W., Valentic, T., Williams, C., and Wyss, P. J.: Development of an autonomous sea ice tethered buoy for the study of ocean-atmosphere-sea ice-snow pack interactions: the O-buoy, Atmos. Meas. Tech., 3, 249-261, 2010, http://www.atmos-meas-tech.net/3/249/2010/.

Kreher, K., Johnston, P. V., Wood, S. W., and Platt, U.: Groundbased measurements of tropospheric and stratospheric $\mathrm{BrO}$ at $\mathrm{Ar}-$ rival Heights ( $\left.78^{\circ} \mathrm{S}\right)$, Antarctica, Geophys. Res. Lett., 24, 30213024, 1997.

Lindberg, S. E., Brooks, S., Lin, C.-J., Scott, K. J., Landis, M. S., Stevens, R. K., Goodsite, M., and Richter, A.: Dynamic Oxidation of Gaseous Mercury in the Arctic Troposphere at Polar Sunrise, Environ. Sci. Technol., 36, 1245-1256, 2002.

McConnell, J. C., Henderson, G. S., Barrie, L., Bottenheim, J., Niki, H., Langford, C. H., and Templeton, E. M. J.: Photochemical bromine production implicated in Arctic boundary-layer ozone depletion, Nature, 355, 150-152, 1992.

Moffat, A. J. and Millán, M. M.: The application of optical correlation techniques to the remote sensing of $\mathrm{SO}_{2}$ plumes using skylight, Atmos. Environ., 5, 677-690, 1971. 
Mount, G. H.: The measurement of tropospheric $\mathrm{OH}$ by long path absorption. 1. Instrumentation, J. Geophys. Res., 97, 2427-2444, 1992.

Platt, U.: Differential optical absorption spectroscopy (DOAS), in: Air Monitoring by Spectroscopic Techniques, Chem. Anal. Ser., edited by: Sigrist, M. W., John Wiley, New York, 127, 27-84, 1994.

Platt, U. and Stutz, J.: Differential Optical Absorption spectroscopy, Principles and Applications, (Physics of Earth and Space Environments), Springer, Berlin, Heidelberg, XV, 597 pp., 272 illus., 29 in color, ISBN 978-3-540-21193-8, 2008.

Richter, A., Wittrock, F., Eisinger, M., and Burrows, J. P.: GOME Observations of Tropospheric BrO in Northern Hemispheric Spring and Summer 1997, Geophys. Res. Lett., 25, 2683-2686, 1998.

Schroeder, W. H., Anlauf, K. G., Barrie, L. A., Lu, J. Y., Steffen, A., Schneeberger, D. R., and Berg, T.: Arctic springtime depletion of mercury, Nature, 394, 331-332, 1998.

Simpson, W. R., von Glasow, R., Riedel, K., Anderson, P., Ariya, P., Bottenheim, J., Burrows, J., Carpenter, L. J., Frie, U., Goodsite, M. E., Heard, D., Hutterli, M., Jacobi, H.-W., Kaleschke, L., Neff, B., Plane, J., Platt, U., Richter, A., Roscoe, H., Sander, R., Shepson, P., Sodeau, J., Steffen, A., Wagner, T., and Wolff, E.: Halogens and their role in polar boundary-layer ozone depletion, Atmos. Chem. Phys., 7, 4375-4418, 2007, http://www.atmos-chem-phys.net/7/4375/2007/.

Simpson, W. R., Carlson, D., Hnninger, G., Douglas, T. A., Sturm, M., Perovich, D., and Platt, U.: First-year sea-ice contact predicts bromine monoxide $(\mathrm{BrO})$ levels at Barrow, Alaska better than potential frost flower contact, Atmos. Chem. Phys., 7, 621-627, $2007 \mathrm{~b}$, http://www.atmos-chem-phys.net/7/621/2007/.

Tang, T. and McConnell, J. C.: Autocatalytic release of bromine from Arctic snow pack during polar sunrise, Geophys. Res. Lett., 23, 2633-2636, 1996.

Tuckermann, M., Ackermann, R., Golz, C., Lorenzen-Schmidt, H., Senne, T., Stutz, J., Trost, B., Unold, W., and Platt, U.: DOASobservation of halogen radical-catalysed arctic boundary layer ozone destruction during the ARCTOC campaigns 1995 and 1996 in Ny-Älesund, Spitsbergen, Tellus, 49B, 533-555, 1997.

Vandaele, A. C., Hermans, C., Simon, P. C., Carleer, M., Colin, R., Fally, S., Merienne, M. F., Jenouvrier, A., and Coquart, B.: Measurements of the NO2 absorption cross-section from $42000 \mathrm{~cm}^{-1}$ to $10000 \mathrm{~cm}^{-1}(238-1000 \mathrm{~nm})$ at $220 \mathrm{~K}$ and 294 K, J. Quant. Spectrosc. Ra., 59, 171-184, 1998. von Glasow, R., von Kuhlmann, R., Lawrence, M. G., Platt, U., and Crutzen, P. J.: Impact of reactive bromine chemistry in the troposphere, Atmos. Chem. Phys., 4, 2481-2497, 2004, http://www.atmos-chem-phys.net/4/2481/2004/.

Wagner, T. and Platt, U., Satellite mapping of enhanced BrO concentrations in the troposphere, Nature, 395, 486-490, 1998.

Wagner, T., Leue, C., Wenig, M., Pfeilsticker, K., and Platt, U.: Spatial and temporal distribution of enhanced boundary layer $\mathrm{BrO}$ concentrations measured by the GOME instruments aboard ERS2, J. Geophys. Res., 106, 24225-24235, 2001.

Wagner, T., Dix, B., v. Friedeburg, C., Frieß, U., Sanghavi, S., Sinreich, R., and Platt, U.: MAX-DOAS $\mathrm{O}_{4}$ measurements: A new technique to derive information on atmospheric aerosols - Principles and Information content, J. Geophys. Res., 109, D22205, doi:10.1029/2004JD004904, 2004.

Wagner, T., Ibrahim, O., Sinreich, R., Frieß, U., von Glasow, R., and Platt, U.: Enhanced tropospheric BrO over Antarctic sea ice in mid winter observed by MAX-DOAS on board the research vessel Polarstern, Atmos. Chem. Phys., 7, 3129-3142, 2007, http://www.atmos-chem-phys.net/7/3129/2007/.

Weidner, F., Bösch, H., Bovensmann, H., Burrows, J. P., Butz, A., Camy-Peyret, C., Dorf, M., Gerilowski, K., Gurlit, W., Platt, U., von Friedeburg, C., Wagner, T., and Pfeilsticker, K.: Balloonborne limb profiling of UV/vis skylight radiances, $\mathrm{O}_{3}, \mathrm{NO}_{2}$, and BrO: technical set-up and validation of the method, Atmos. Chem. Phys., 5, 1409-1422, 2005, http://www.atmos-chem-phys.net/5/1409/2005/.

Wilmouth, D.M., T.F. Hanisco, N.M. Donahue, and J.G. Anderson, Fourier transform ultraviolet spectroscopy of the $\mathrm{A}\left({ }^{\mathrm{y}} \Pi_{3 / 2}\right)$ $<-\mathrm{X}\left({ }^{\mathrm{y}} \Pi_{3 / 2}\right)$ transition of BrO, J. Phys. Chem., 103, 89358944, 1999.

Wittrock, F., Müller, R., Richter, A., Bovensmann, H., and Burrows, J. P.: Observations of Iodine monoxide above Spitsbergen, Geophys. Res. Lett., 27(10), 1471-1474, 2000.

Wittrock, F., Oetjen, H., Richter, A., Fietkau, S., Medeke, T., Rozanov, A., and Burrows, J. P.: MAX-DOAS measurements of atmospheric trace gases in Ny-Ålesund - Radiative transfer studies and their application, Atmos. Chem. Phys., 4, 955-966, 2004, http://www.atmos-chem-phys.net/4/955/2004/. 